\title{
Radiographic study of fluid transport in the rabbit vas deferens during sexual rest and after sexual activity
}

\author{
Gail S. Prins* and L. J. D. Zaneveld \\ Department of Physiology and Biophysics, University of Illinois at the Medical Center, \\ P.O. Box 6998 Chicago, Illinois 60680, U.S.A.
}

\begin{abstract}
Summary. The movement of radio-opaque medium in the vas deferens of rabbits during sexual rest, after sexual stimulation, and after ejaculation, was followed. Bilateral injections of $20 \mu \mathrm{l}$ Ethiodol were given at the vas-epididymal junction in the urethral direction. Serial radiographs revealed proximal transport of the dye (towards the testis) within $24 \mathrm{~h}$ and total containment in the cauda epididymidis within 1-4 days. Subsequently, small amounts of dye moved from the epididymis through the vas and out of the urethra during sexual rest until no dye remained (11 days-8 weeks). Animals with a ligated vas deferens showed no decrease in dye density. Sexual stimulation moved the dye from the epididymis into the vas. The dye was then either rapidly transported proximally during subsequent rest or removed distally if ejaculation followed stimulation. Ejaculation removed some vasal and epididymal dye via the urethra; however, dye left in the vas after ejaculation was rapidly $(<30 \mathrm{~min}$ ) transported to the proximal duct and then into the epididymis by $24 \mathrm{~h}$. It is concluded that vasal contents are transported in both urethral and testicular directions during sexual rest and that, after stimulation and ejaculation, the rate of proximal transport is increased. This may be indicative of a sperm removal mechanism by the vas deferens which involves the maintenance of an optimal sperm number in the cauda epididymidis at all times.
\end{abstract}

\section{Introduction}

Recently, we investigated the changing sperm numbers and distribution patterns in the rabbit vas deferens during sexual rest and following sexual activity in an attempt to define sperm transport in more detail (Prins \& Zaneveld, 1979). Our results indicated that during sexual rest spermatozoa are transported through the vas deferens and into the urethra. Such transport provides a mechanism for removing excess spermatozoa which are not voided by ejaculations. The spermatozoa present in the vas deferens were located primarily in the proximal region of the duct with a decreasing gradient towards the urethral end. When that observed distribution pattern changed, as after sexual stimulation and/or ejaculation, it was restored within $48 \mathrm{~h}$, indicating active redistribution of spermatozoa within the vas deferens during sexual rest. Upon sexual stimulation, spermatozoa stored in the cauda epididymidis were transported into the vas deferens in amounts large enough to supply an ejaculate. It was therefore postulated that spermatozoa are moved from the epididymal reservoir into the vas deferens before emission and that, at emission, spermatozoa are rapidly transported out of the vas deferens into the urethra. We have now followed the movement of radio-opaque medium in the vas deferens to study the transport of vasal contents in more detail. Apart from a limited study by Wilhelm (1935), a radiographic technique of this sort has not previously been applied to the vas deferens.

* Present address: Department of Urology, Northwestern University Medical School, Chicago, Illinois 60611, U.S.A. 


\section{Materials and Methods}

New Zealand White sexually mature males, at least 8 months of age (Amann \& Lambiase, 1967 ) and weighing $3.5-4.0 \mathrm{~kg}$, were housed in separate cages in the same room and fed rabbit chow and water ad libitum. Semen was collected by artificial vagina every $48 \mathrm{~h}$ for 2-3 weeks before the experiment to standardize the sexual activity of the males. Spermatozoa were counted with a haemocytometer to obtain the total sperm output in each ejaculate.

At the beginning of the procedure, the rabbit was anaesthetized intravenously with $2.5 \%$ sodium thiamylal (Surital: Parke-Davis, Detroit, Michigan) and a control anterior-posterior radiograph of the pelvic region was taken. Using sterile techniques, a lateral scrotal incision was made and the vas-epididymal junction was isolated. The radio-opaque material was Ethiodol (Savage Laboratory, Missouri City, Texas), an iodinated poppyseed oil, and $20 \mu \mathrm{l}$ were slowly injected into the lumen of the vas deferens at its junction with the epididymis. The vas deferens was handled minimally at this time so as not to disturb the nerve or blood supply. The injection was made in the urethral direction using a calibrated microcapillary pipette attached to a 23 gauge minicath infusion set (Deseret Co., Sandy, Utah). A metal ligaclip (Ethicon) was attached to surrounding connective tissue and used as a marker for the injection site. After the duct was carefully returned to its natural position in the scrotal sac, the tunica albuginea and the skin were closed separately with interrupted sutures of 3-0 Dexon. A post-injection radiograph was then taken followed by X-rays at 6, 24, 48 and $72 \mathrm{~h}$. Subsequent radiographs were taken at 1-3-day intervals until the experiment was terminated. A Westinghouse Veriflex X-ray machine was used to expose the X-ray film (Kodak Blue Brand) at the following settings: $72 \mathrm{kV}, 200 \mathrm{~mA}$ D.C., $1 / 15 \mathrm{sec}$ exposure.

After this injection-radiographic procedure was refined in 5 test animals, it was performed 32 times with 28 rabbits. The animals were divided into 5 groups. Group A consisted of 6 rabbits in which the movement of the dye was followed during sexual rest until it was cleared from the system. Group B (4 rabbits) served as a control for the absorption of the dye by the body. Before the injection of the dye into the vas deferens a ligaclip was placed over one vas distal to the injection site, completely occluding the lumen of the vas and thereby preventing the transport of any contrast material through the vas. The other side was treated as described for Group A.

Group $\mathrm{C}$ was composed of 7 rabbits who were injected with the dye as described for Group $\mathrm{A}$ and then ejaculated when the dye appeared as a concentrated, dense image or a dispersed, uncoiled image. Pre- and post-ejaculation radiographs were taken. Ejaculations were continued on subsequent days until all the dye was removed.

Group D (12 animals) was for study of the effects of sexual stimulation and to observe any subsequent transport during sexual rest after stimulation without ejaculation. At 4-6 days after injection, a radiograph was taken and the animal was subsequently sexually stimulated by allowing mounting of an ovariectomized female but preventing ejaculation. Radiographs were then taken within $30 \mathrm{sec}$ and at 5, 10, 15, 20, 25 and $30 \mathrm{~min}$ and 6-24 h after stimulation. The animal was restrained in the supine position on the $\mathrm{X}$-ray table to prevent movement.

The 3 animals in Group E were ejaculated after sexual stimulation to observe the removal of the vasal contents upon ejaculation. At $24 \mathrm{~h}$ after injection, each rabbit was X-rayed, sexually stimulated, immediately $X$-rayed, ejaculated, and again $X$-rayed immediately and at 5, 10, 30 and $60 \mathrm{~min}$ and $24 \mathrm{~h}$ later. The later radiographs recorded movement of remaining vasal contents during sexual rest following ejaculation.

To determine the influence of fluid viscosity on the pattern of flow observed in the vas deferens, 2 rabbits were injected with Lipiodol (Savage Lab, Missouri City, Texas), an iodinated poppyseed oil with a viscosity 20 times geater than that of Ethiodol. One animal from Group A and one from Group $\mathrm{C}$ were used for this test. The viscosity of Ethiodol, Lipiodol and epididymal fluid (collected and pooled from 4 rabbits) was measured with a semi-micro viscosimeter (Model 300; Sargent-Welch, Skokie, Illinois). 
To check that the surgery caused minimal tissue trauma at the injection site, the vas deferens was removed from a rabbit $24 \mathrm{~h}$ after surgery and prepared for histological examination (6 $\mu \mathrm{m}$ sections, haematoxylin and eosin stain).

The intraluminal pressure changes resulting from the injection were recorded in one experiment. A micro-tip pressure transducer (Millar, Houston, Texas) was inserted into the lumen of the abdominal vas deferens $5 \mathrm{~cm}$ from the injection site. Pressure, which was monitored via the transducer on a Grass Polygraph (Model 79D), was measured for 15 min after the injection of 25 and $50 \mu$ Ethiodol.

\section{Results}

In all the rabbits, the dye injected into the vas deferens was transported proximally (towards the testis) within hours after surgery (Tables 1-3). In Groups A-D, this proximal movement continued until the dye was located in the cauda epididymidis or, in a few cases, near the injection site. Subsequently, the dye was slowly removed via the urethra during sexual rest or rapidly during the ejaculatory process.

\section{Group $A$}

Plate 1 depicts the typical radio-opaque dye movement in the vas deferens during sexual rest. The dye present within the vas deferens after injection (Plate 1, Fig. 1) was slowly transported in the proximal direction until it was all contained within the cauda epididymidis (PI. 1, Fig. 2). The epididymal image slowly faded away (Pl. 1, Fig. 3) until after 3 weeks (in this animal) no dye remained in the duct (Pl. 1, Fig. 4). During this period of fading, the image of the epididymis was seen in two states: (1) as a tight, concentrated mass, or (2) in a dispersed, uncoiled state. It was in the latter state when dye was occasionally seen being released from the epididymis into the vas deferens (Pl. 2, Figs 5-7). The dye seen in the right and left proximal vas in Pl. 2, Fig. 5 was found in the abdominal and distal vas $24 \mathrm{~h}$ later (Pl. 2, Fig. 6) and removed from the duct within the next 5 h (Pl. 2, Fig. 7).

All the rabbits in Group A showed the same dye movement, but there were variations in the time course (Table 1). Proximal movement (approximately $1-4 \mathrm{~cm}$ ) was always visible within

Table 1. Time course of the movement of radio-opaque dye injected into the vas deferens of rabbits during subsequent sexual rest (Group A)

\begin{tabular}{clccc}
\hline Rabbit & Side & $\begin{array}{c}\text { Start of } \\
\text { proximal movement } \\
\text { in vas deferens (h) }\end{array}$ & $\begin{array}{c}\text { Time when } \\
\text { dye all in } \\
\text { epididymis }\end{array}$ & $\begin{array}{c}\text { Time for complete } \\
\text { removal of dye } \\
\text { from epididymis }\end{array}$ \\
\hline 1 & Left & 6 & $48 \mathrm{~h}$ & 3 weeks \\
& Right & 6 & $48 \mathrm{~h}$ & 3 weeks \\
$2^{*}$ & Left & 24 & $72 \mathrm{~h}$ & 3.5 weeks \\
& Right & 24 & $48 \mathrm{~h}$ & 4 weeks \\
3 & Left & 6 & $\begin{array}{c}\text { Only to } \\
\text { injection }\end{array}$ & $48 \mathrm{~h}$ \\
& Right & 6 & site & $72 \mathrm{~h}$ \\
& & & Only to & $72 \mathrm{~h}$ \\
4 & Left & 24 & injection & 5 days \\
& Right & 24 & $72 \mathrm{~h}$ & 7 weeks \\
& & & 19 days & 7 weeks \\
5 & Left & 6 & $48 \mathrm{~h}$ & 11 days \\
& Right & 6 & $72 \mathrm{~h}$ & 8 weeks \\
\hline
\end{tabular}

* Lipiodol used. All others injected with Ethiodol. 
the first $24 \mathrm{~h}$. With the exceptions of Rabbits 3 and 4 in which proximal movement stopped near the injection site, the dye was slowly transported past the injection site and into the cauda epididymidis within 48 to $72 \mathrm{~h}$. In the right vas of Rabbit 5, proximal movement stopped at the most proximal part of the vas deferens after 5 days of slow backwards movement and remained there for 19 days while it faded in density due to distal passage of some of the dye through the vas deferens. At 19 days after injection, the remaining dye was transported back into the cauda epididymidis. The dye which was retained in the epididymis of the rabbits eventually disappeared at times ranging from 11 days to 8 weeks. In the 2 rabbits in which the dye did not reach the epididymis, the medium was cleared from the tract within 2-5 days.

\section{Group B}

In each rabbit all the dye in the ligated tract after injection was contained within the epididymis and although the image fluctuated between partial concentration and dispersion there was no change in density even after 8 weeks. The dye movement in the contralateral, non-ligated side was similar to that for Group A. Table 2 summarizes the events in Group B. Proximal movement was seen in the non-ligated side of each rabbit within $24 \mathrm{~h}$ of surgery. All the dye was contained within the epididymis on this side for 3-4 days except for Rabbit 9 in which the movement took 2 weeks. The dye gradually disappeared in these non-ligated sides between 5 and 8 weeks. The dye did not decrease in density in the epididymis of any of the ligated tracts.

Table 2. Time course of the movement of radio-opaque dye injected into the vas deferens of rabbits during subsequent sexual rest with one side ligated distal to the injection site (Group B)

\begin{tabular}{|c|c|c|c|c|}
\hline Rabbit & Side & $\begin{array}{c}\text { Start of } \\
\text { proximal movement } \\
\text { in vas deferens (h) }\end{array}$ & $\begin{array}{l}\text { All in } \\
\text { epididymis }\end{array}$ & $\begin{array}{l}\text { Time for complete } \\
\text { removal of dye } \\
\text { from epididymis }\end{array}$ \\
\hline 7 & $\begin{array}{l}\text { Left } \\
\text { Right }\end{array}$ & $\begin{array}{l}\text { (Ligated) } \\
6\end{array}$ & $\overline{4}$ days & $\begin{array}{l}\text { No fading } \\
7 \text { weeks }\end{array}$ \\
\hline 8 & $\begin{array}{l}\text { Left } \\
\text { Right }\end{array}$ & $\begin{array}{l}6 \\
\text { (Ligated) }\end{array}$ & $\frac{72 \mathrm{~h}}{-}$ & $\begin{array}{l}5.5 \text { weeks } \\
\text { No fading }\end{array}$ \\
\hline 9 & $\begin{array}{l}\text { Left } \\
\text { Right }\end{array}$ & $\begin{array}{l}24 \\
\text { (Ligated) }\end{array}$ & 2 weeks & $\begin{array}{l}5 \text { weeks } \\
\text { No fading }\end{array}$ \\
\hline 10 & $\begin{array}{l}\text { Left } \\
\text { Right }\end{array}$ & $\begin{array}{l}\text { (Ligated) } \\
6\end{array}$ & $\overline{72} \mathrm{~h}$ & $\begin{array}{l}\text { No fading } \\
8 \text { weeks }\end{array}$ \\
\hline
\end{tabular}

\section{PLATE 1}

Radiographs showing proximal movement of radio-opaque dye in a Group A rabbit after injection into the vasa deferentia followed by its gradual disappearance during sexual rest. The scrotal markers can be clearly seen.

Fig. 1. Post-injection radiograph reveals opaque vasa.

Fig. 2. By 4 days after injection all dye is in the cauda epididymidis.

Fig. 3. By 10 days after injection, the dye is decreasing in density, presumably due to transport through the vas deferens.

Fig. 4. By 3 weeks after injection, all dye has gone.

\section{PLATE 2}

Sequential radiographs revealing movement of some radio-opaque dye from the cauda epididymidis into the vas deferens and out of the tract. Arrows indicate the areas of dye.

Fig. 5. Dye in the cauda epididymidis and at the vas-epidymal junction.

Fig. 6. Dye formerly at the junction and now within the abdominal vas and ampulla $24 \mathrm{~h}$ later.

Fig. 7. By $5 \mathrm{~h}$ later all the dye in the vas is gone. 


\section{PLATE 1}
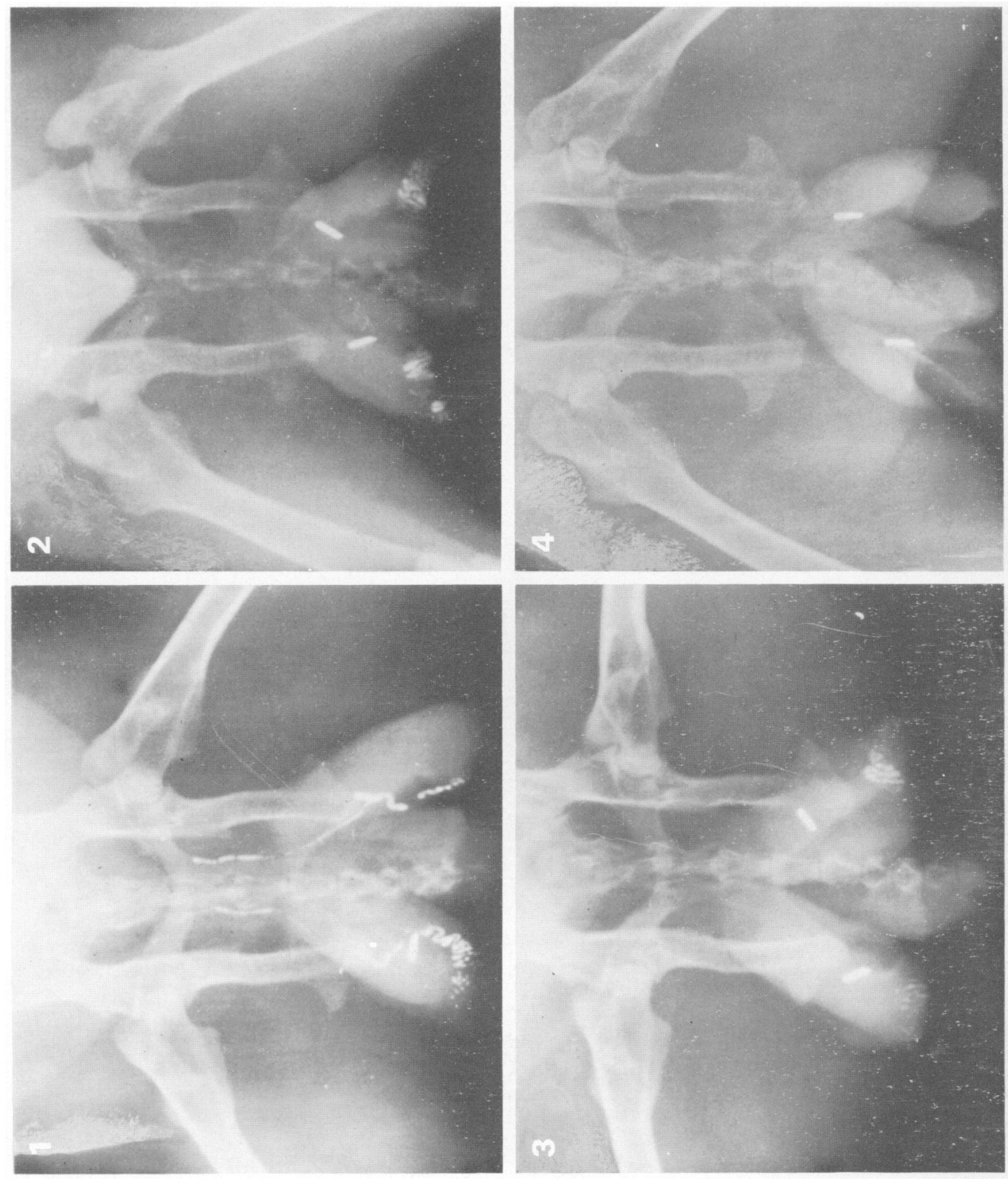

(Facing p. 314) 
PLATE 2
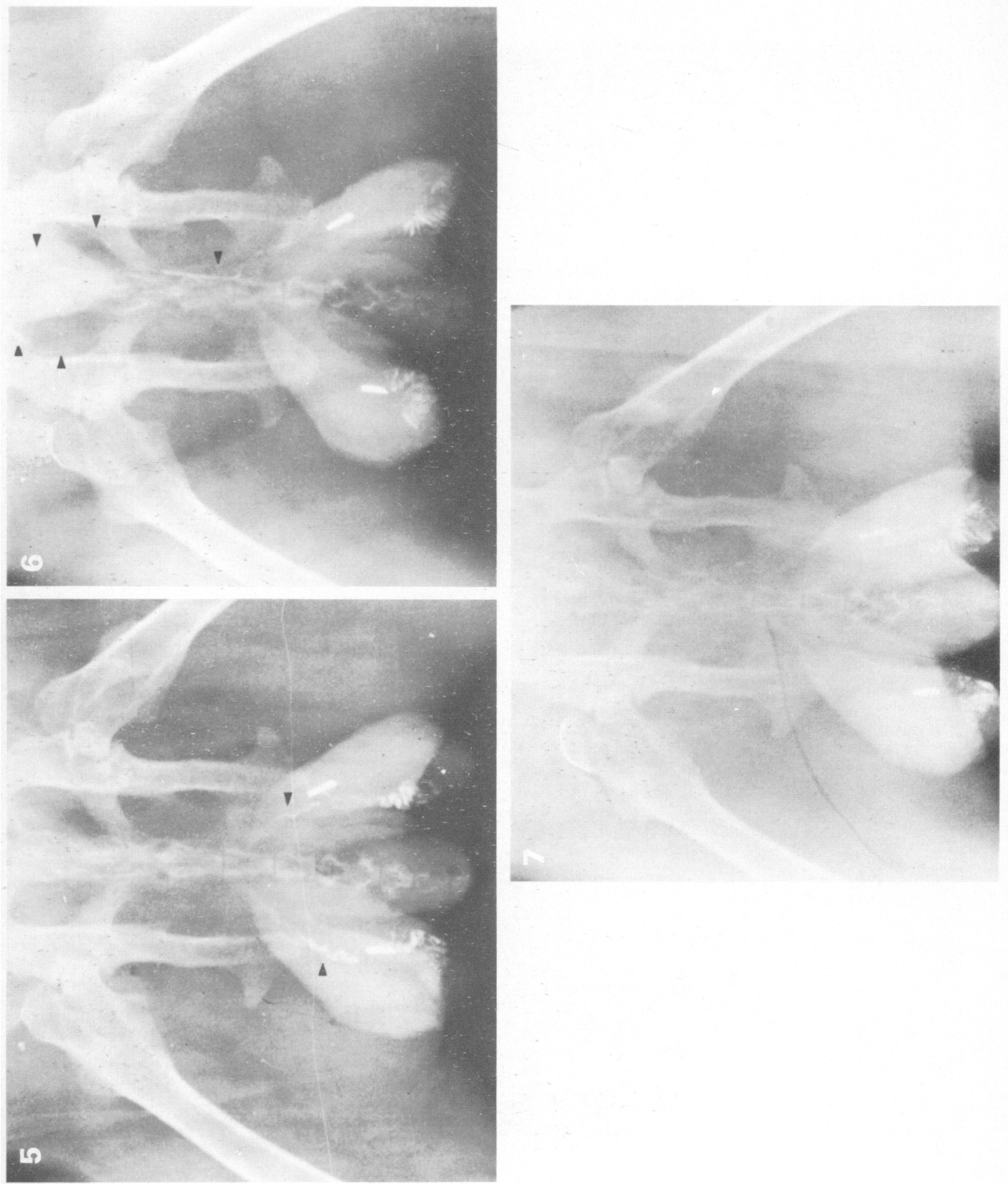
PLATE 3
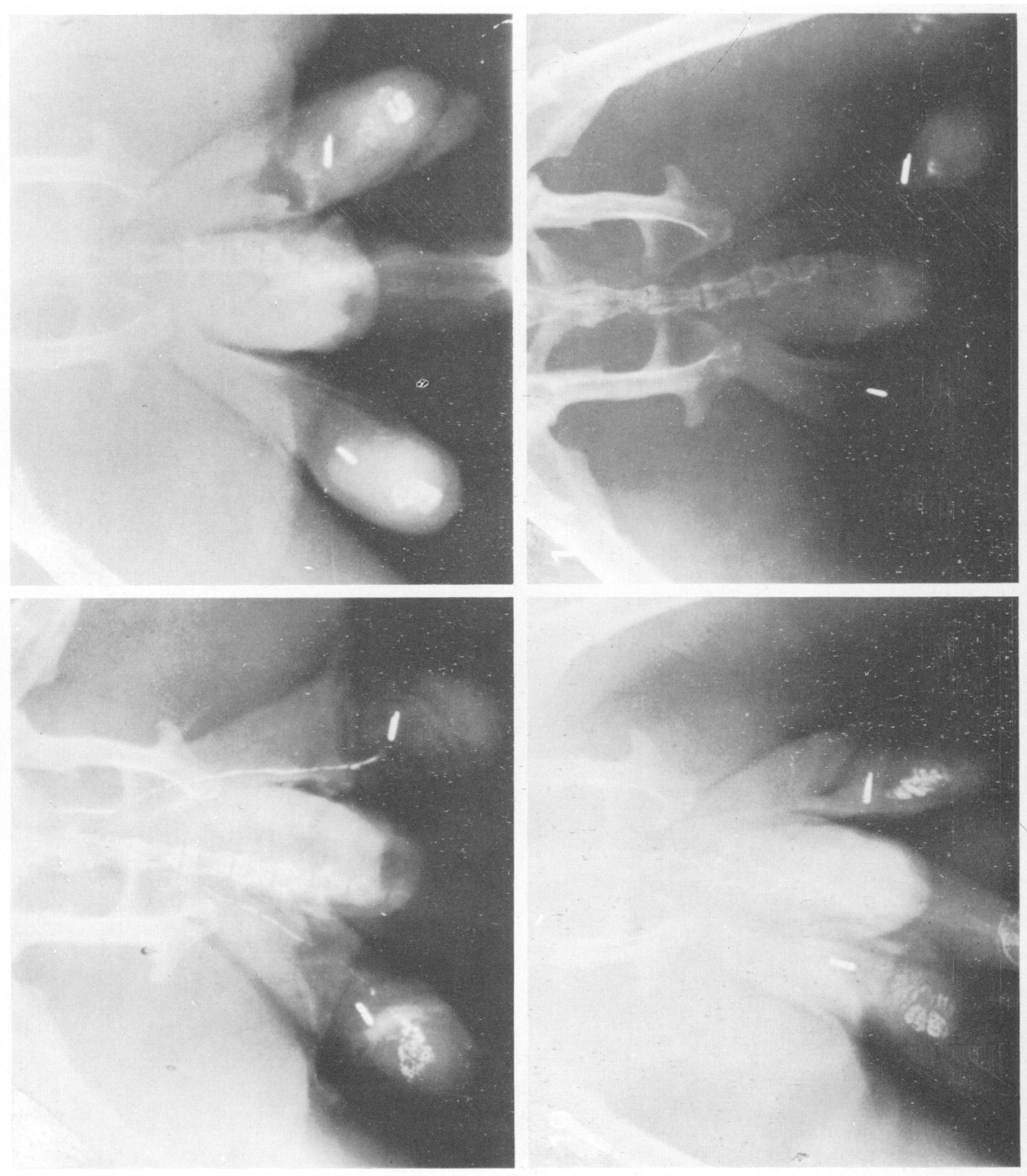
PLATE 4
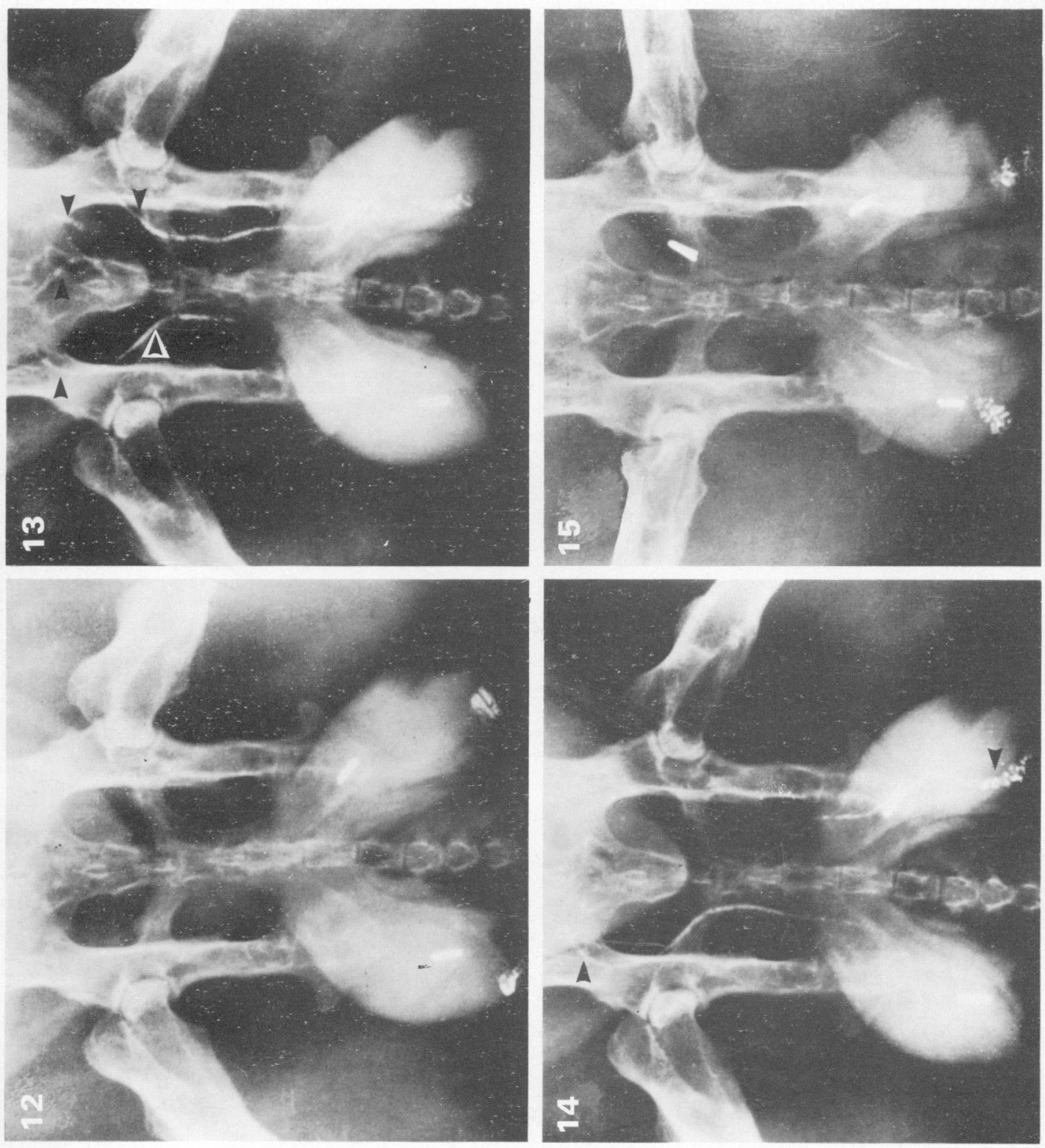


\section{Group C}

Backwards movement of the dye to the epididymis was observed as in Group A. Since epididymal dye in each animal was seen at some times in a dispersed state and at others in a tight, concentrated state, the rabbits of this group were ejaculated to ascertain the movement of the dye in either of these states. The radiographs in Plate 3 illustrate the stages typically seen. After injection (Pl. 3, Fig. 8), the dye in the vas deferens was slowly transported proximally until, by Day 5, the dye was contained in the epididymis (Pl. 3, Fig. 9). This image moved deep into the cauda epididymidis and was concentrated into a tight mass by Day 8 . During the next week, the dye dispersed (Pl. 3, Fig. 10) and then concentrated several times. When the image was in the dispersed state on Day 20, the animal was ejaculated and a post-ejaculation radiograph (Pl. 3, Fig. 11) revealed the removal of most of the dye. Ejaculation $24 \mathrm{~h}$ later cleared the rest of the dye from the tract. Such removal was typical when the epididymis appeared dispersed at the time of ejaculation. Other rabbits were ejaculated when the epididymal images were concentrated: in these, the bulk of the dye was not removed and several ejaculations (performed every other day) were required to clear the dye although the image decreased in density after each ejaculation.

Table 3 summarizes the results in Group C. Proximal movement began in all but Rabbit 13 within the first $24 \mathrm{~h}$. This transport continued until only the epididymis was outlined by the dye, with 2 exceptions (No. 12 right and No. 15 right) in which proximal movement stopped near the injection site. In most cases, epididymal containment required up to 3 days. In the left vas deferens of Rabbit 17 and the left and right vasa of Rabbit 13, the proximal movement of dye stopped in the proximal vas deferens for several days before continuing into the epididymis. The dye in the right side of Rabbit 17 probably became trapped in the epididymis since up to 20 ejaculations failed to move the dye. The ejaculates of all these rabbits contained normal amounts of spermatozoa.

\section{Group D}

As in Groups A-C, the dye injected into the vasa of these rabbits was transported proximally for 2-4 days until it was contained within the cauda epididymidis. Sexual stimulation moved this dye into the vas deferens (Plate 4). Dye contained in the epididymis (Pl. 4, Fig 12) was transported into the right distal and ampullary vas deferens and the left proximal-distal-

\section{PLATE 3}

Radiographs showing proximal movement of radio-opaque dye in a Group $\mathrm{C}$ rabbit after injection into the vasa deferentia and its removal after one ejaculation when the epididymides were visualized in a dispersed, uncoiled state.

Fig. 8. Radiograph after injection reveals partly opaque vasa.

Fig. 9. By 5 days after injection, all dye is in the cauda epididymidis.

Fig. 10. The dispersed uncoiled image of the cauda before ejaculation.

Fig. 11. Radiograph after ejaculation reveals almost complete removal of dye.

PLATE 4

Radiographs showing distal transport of epididymal dye into the vasa deferentia of a rabbit in Group D after sexual stimulation and the proximal movement back into the epididymides during the subsequent period of sexual rest. Arrows indicate the dye.

Fig. 12. Pre-stimulatory radiograph showing dye in the cauda epididymidis.

Fig. 13. Immediately after sexual stimulation the dye is in the vasa deferentia.

Fig. 14. At $10 \mathrm{~min}$ after stimulation, proximal movement is apparent.

Fig. 15. By $7 \mathrm{~h}$ after stimulation almost all the dye is back in the epididymides. 
Table 3. Time course of the movement of radio-opaque dye injected into the vas deferens of rabbits during subsequent sexual rest followed by ejaculations (Group C)

\begin{tabular}{|c|c|c|c|c|c|c|}
\hline Rabbit & Side & $\begin{array}{c}\text { Start of } \\
\text { proximal } \\
\text { movement } \\
\text { in vas } \\
\text { deferens (h) }\end{array}$ & $\begin{array}{l}\text { Time when } \\
\text { dye all in } \\
\text { epididymis }\end{array}$ & $\begin{array}{l}\text { Amount of } \\
\text { rest } \\
\text { before first } \\
\text { ejaculation }\end{array}$ & $\begin{array}{l}\text { State of } \\
\text { epididymal } \\
\text { image at } \\
\text { ejaculation }\end{array}$ & $\begin{array}{l}\text { No. of } \\
\text { ejaculations } \\
\text { to remove } \\
\text { all dye from } \\
\text { system }\end{array}$ \\
\hline 11 & $\begin{array}{l}\text { Left } \\
\text { Right }\end{array}$ & $\begin{array}{l}6 \\
6\end{array}$ & $\begin{array}{l}72 \mathrm{~h} \\
48 \mathrm{~h}\end{array}$ & $\begin{array}{l}3 \text { weeks } \\
3 \text { weeks }\end{array}$ & $\begin{array}{l}\text { Dispersed } \\
\text { Dispersed }\end{array}$ & $\begin{array}{l}2 \\
2\end{array}$ \\
\hline 12 & $\begin{array}{c}\text { Left } \\
\text { Right } \S\end{array}$ & $\begin{array}{l}6 \\
6\end{array}$ & $\begin{array}{l}24 \mathrm{~h} \\
\text { Only to } \\
\text { injection } \\
\text { site }\end{array}$ & 2 weeks & $\begin{array}{c}\text { Dispersed } \\
-\end{array}$ & $\frac{3}{-}$ \\
\hline 13 & $\begin{array}{l}\text { Left } \\
\text { Right }\end{array}$ & $\begin{array}{l}72 \\
72\end{array}$ & $\begin{array}{r}9 \text { days } \\
14 \text { days }\end{array}$ & $\begin{array}{l}2 \text { weeks } \\
2 \text { weeks }\end{array}$ & $\begin{array}{c}\text { Dispersed } \\
\text { Concentrated }\end{array}$ & $\begin{array}{l}1 \\
7\end{array}$ \\
\hline 14 & $\begin{array}{c}\text { Left } \\
\text { Right }\end{array}$ & 24 & $\stackrel{72 \mathrm{~h}}{-}$ & 2 weeks & Concentrated & 10 \\
\hline 15 & $\begin{array}{l}\text { Left } \dagger \\
\text { Right }\end{array}$ & $\overline{24}$ & $\begin{array}{l}-\overline{-} \\
\text { Only to } \\
\text { injection } \\
\text { site }\end{array}$ & 5 days & $\begin{array}{l}\text { Image in } \\
\text { proximal } \\
\text { vas }\end{array}$ & $\overline{1}$ \\
\hline $16 \ddagger$ & $\begin{array}{l}\text { Left } \S \\
\text { Right }\end{array}$ & $\begin{array}{l}6 \\
6\end{array}$ & $\begin{array}{l}48 \mathrm{~h} \\
48 \mathrm{~h}\end{array}$ & 6 weeks & Semi-dispersed & $\overline{3}$ \\
\hline 17 & $\begin{array}{l}\text { Left } \\
\text { Right }\end{array}$ & $\begin{array}{l}6 \\
6\end{array}$ & $\begin{array}{l}11 \text { days } \\
72 \mathrm{~h}\end{array}$ & $\begin{array}{l}4 \text { weeks } \\
4 \text { weeks }\end{array}$ & $\begin{array}{l}\text { Semi-dispersed } \\
\text { Concentrated }\end{array}$ & $\begin{array}{c}2 \\
\text { (Trapped) }\end{array}$ \\
\hline
\end{tabular}

* Rabbit was unilaterally castrated after complications.

$\uparrow$ Not injected.

$¥$ Lipiodol used. All others injected with Ethiodol.

$\S$ Dye removed during sexual rest.

ampullary vas deferens upon sexual stimulation (PI. 4, Fig. 13). Proximal movement of the dye was seen in the left duct within 5 min after stimulation and more so in both sides by 10 min (PI. 4, Fig. 14). This proximal transport slowly continued until by $7 \mathrm{~h}$ (in this animal) most of the dye was again contained within the cauda epididymidis (Pl. 4, Fig. 15).

All the animals in this group showed the same movement patterns with variations in the distance of distal dye transport after stimulation and in the time course of proximal transport during subsequent sexual rest. In some animals, dye reached only to the proximal-distal region of the vas after sexual stimulation, in others it opacified the entire tubular vas and the ampulla, and in yet others it was seen in only the distal-ampullary portions. Proximal transport was apparent in all animals within 5-10 min after stimulation. Time for complete epididymal containment varied between $15 \mathrm{~min}$ and $24 \mathrm{~h}$ of sexual rest and was generally $6-8 \mathrm{~h}$. This was sometimes, but not always, related to the distance the dye had been moved forward during sexual stimulation. Proximal transport always took place with greater rapidity during the sexual rest period following stimulation than it did during total sexual rest (Group A).

\section{Group $E$}

Following injection, the dye in the vas deferens was transported proximally to the vas deferens-epididymal junction by $24 \mathrm{~h}$ in each animal. Sexual stimulation resulted in the transport of dye into the vas deferens so that the tract was opacified on both sides, as seen in Group D. Subsequent ejaculation resulted in (1) the removal of a significant amount of the vasal dye and (2) the transport of the dye remaining in the epididymis after stimulation into the vas deferens. Within 10 min after ejaculation, the dye in the vas deferens showed definite signs of 
proximal transport which continued until it was all contained within the epididymis ( 30 min$24 \mathrm{~h})$.

\section{Viscosity, tissue damage, and injection pressure}

The 2 rabbits injected with the more viscous Lipiodol in Groups A and C showed the same transport patterns with comparable time periods as those injected with Ethiodol (Tables 1 and 3). The viscosities of the fluids were 414.72 (Lipiodol), 119.96 (epididymal fluid), and 24.45 (Ethiodol) $\mathrm{cSt}\left(\times 10^{-6} \mathrm{~m}^{2} / \mathrm{s}\right)$.

Histological sections of the vas deferens at the injection site $24 \mathrm{~h}$ after surgery revealed a patent lumen and no tissue trauma.

Intraluminal pressure recordings during injection of 25 and $50 \mu \mathrm{l}$ Ethiodol showed transient increases of 2.25 and $7.70 \mathrm{cmH}_{2} \mathrm{O}$, respectively. This rise in pressure lasted approximately 15 sec. Within $2 \mathrm{~min}$, the intraluminal pressures returned to the preinjection level. Contractions of the vas deferens were not initiated with this injection procedure.

\section{Discussion}

In 1935, Wilhelm injected radio-opaque dye into the vas deferens of vasectomized men and observed a gradual fading of the vasal image over the next month. However, his data are not adequate to permit conclusions about sperm transport and transport patterns in the vas deferens since his subjects were surgically manipulated, few radiographs were taken, and dye removal via absorption or ejaculation was not controlled. The present radiographic investigation, by documenting the events in detail, has established that the contents of the cauda epididymidis and the vas deferens are slowly transported out of the rabbit via the urethra during sexual rest. This, together with our previous work (Prins \& Zaneveld, 1979), strongly supports the theory that excess spermatozoa (in the epididymis) are removed via the vas deferens (Holtz \& Foote, 1972, 1974).

The present data suggests a complex random or cyclic mechanism of sperm removal rather than a constant outward trickle during sexual rest. Fluid injected into the vas deferens was initially transported in the proximal direction rather than distally (towards the urethra) as was expected. Transport in the proximal direction has previously been suggested by Van Welkenhuyzen (1966) who demonstrated, by exogenous stimulation, that contractions of the vas deferens can be propagated in the testicular direction. In our study, after the dye was contained within the cauda epididymis, it dispersed in small amounts at irregular intervals and not as a continuous stream. The notion that sperm removal through the vas is random or cyclic is supported by the work of Holtz \& Foote (1972) in which dramatic day-to-day fluctuations were observed in the numbers of spermatozoa in rabbit urine.

While the dye was being removed from the epididymis, the image was either dispersed and, at times, releasing dye towards the proximal vas deferens, or was a dense mass. These images appear to be a reflection of two functional states of the epididymis; the first when it is removing excess spermatozoa and the second when the contents are being retained. This hypothesis is supported by the data obtained from animals ejaculated immediately after the epididymal image appeared in one of these two states. When the dye appeared in the condensed state, only a faint decrease, if any, was observed in the image after ejaculation and a number of ejaculations were necessary to remove the dye from the animal. When the dye appeared in the dispersed state, a marked decrease in contrast occurred after ejaculation and few subsequent ejaculations were required to remove all the dye.

The proximal transport phenomenon reported does not appear to be an artefact resulting from the procedure itself. Histological slides of the vas at $24 \mathrm{~h}$ post-injection revealed a patent 
lumen, and pressure recordings showed that the increase in intraluminal pressure after injection was minimal, dissipated rapidly and did not induce contractions, thereby ruling out stretch as a stimulatory factor. Additionally, proximal transport occurred after stimulation and ejaculation when there was no external interference. One cannot assume that Ethiodol exactly mimicked the flow of spermatozoa. However, since the pattern of Lipiodol movement was essentially the same as that of Ethiodol even though they have different viscosities and since the viscosity of spermatic fluid is between that measured for the two dyes, it is highly probable that the dye movement simulated the natural flow patterns in the vas-epididymal system.

Prins \& Zaneveld (1979) have shown that the vas deferens filled with spermatozoa from the cauda epididymidis during sexual stimulation and suggested that the vasa, which then contain adequate amounts of spermatozoa, are the direct source of spermatozoa at the time of emission. Their data also indicated that the caudal reservoir replenishes the vas deferens with spermatozoa as the vas empties during the ejaculatory process. The hypothesis is now supported by the results of the present radiographic study in which the X-rays revealed when and where the epididymalvasal contents are moved during sexual stimulation and ejaculation. Sexual stimulation moves epididymal dye forward into the vas deferens including the distal and, in some cases, the ampullary portions. Subsequent ejaculation removes this dye from the vas deferens and transports some of the dye that had remained in the epididymis after stimulation into the vas deferens.

Following sexual stimulation (with no ejaculation) and immediately after ejaculation when the distal vasal sperm content is increased and the epididymal sperm number decreased (Prins \& Zaneveld, 1979), proximal transport of the vasal contents was consistently observed in the present study. Under these conditions, proximal transport of the vasal contents into the epididymis was more rapid than during sexual rest; beginning within minutes after termination of sexual activity and ending within hours, as opposed to hours to begin and days to terminate during total sexual rest. It appears that the causative factors inducing and allowing such transport are heightened at the time of sexual activity. This observation explains the redistribution pattern of spermatozoa in the vas deferens seen during the initial rest period following ejaculation as reported by Prins \& Zaneveld (1979). The increase in scrotal vas deferens sperm numbers with the concurrent decrease in abdominal and ampullary vas deferens numbers after $48 \mathrm{~h}$ of sexual rest is due to the proximal transport of vasal contents which begins soon after ejaculation.

The results of the present experiments suggest that open-ended, continuous sperm transport through the vas deferens does not take place during sexual rest. Since it appears that the vas deferens is capable of both distal and proximal transport, it is postulated that the vas-epididymal system not only removes spermatozoa, but conserves them as well. The sperm distribution study (Prins \& Zaneveld, 1979) showed that during sexual inactivity (i.e. most of the time) the epididymis and proximal vas deferens contained the largest numbers of spermatozoa, while only a small percentage was contained within the distal portions. This sperm distribution gradient was held constant at rest. When the epididymal-vasal contents were moved forward into the distal vas deferens, as occurred after injection of dye, sexual stimulation, and ejaculation, the changed distribution was eventually restored through proximal transport. The initiation and maintenance of a gradient which keeps spermatozoa away from the urethral opening is indicative of a conservation mechanism which attempts to maintain an optimal supply of spermatozoa in the epididymal reservoir at all times that are available for release into an ejaculate. The state of fullness of the epididymis/vas deferens would determine this optimal content, possibly via a volume/pressure feedback.

It is suggested that when the cauda epididymidis is not full, its contents are increased by the constant daily sperm production, the proximal transport of vasal spermatozoa, and by lack of removal of spermatozoa through the vas deferens. When the contents are optimal, the excess is transported out through the vas deferens during sexual rest. Such a mechanism would explain 
the observation that in some animals the injected dye was not transported all the way back into the epididymis, while in others the dye was either immediately transported to the cauda epididymidis or was first held at the proximal vas deferens and then transported backwards. This mechanism could also account for the large variability in time for complete removal of dye at rest.

In conclusion, these data indicate that the vas deferens is a dynamic organ which is active during sexual rest, possibly aiding the regulation of sperm reserves in the male reproductive tract. This is particularly important in light of the current interest in reversing vasectomies and developing vas deferens contraceptive devices.

We are deeply indebted to Dr R. L. Vogelzang and Dr S. F. Marotta for their advice and assistance and thank Dr B. T. Bennett and Dr R. L. Vogelzang for suplying the radiological equipment.

\section{References}

Amann, R.P. \& Lambiase, J.T. (1967) The male rabbit. I. Changes in semen characteristics and sperm output between puberty and one year of age. $J$. Reprod. Fert. 14, 329-332.

Holtz, W. \& Foote, R.G. (1972) Sperm production, output and urinary loss in the rabbit. Proc. Soc. exp. Biol. Med. 141, 958-962.

Holtz, W. \& Foote, R.G. (1974) Cannulation and recovery of spermatozoa from the rabbit ductus deferens. J. Reprod. Fert. 39, 89-92.
Prins, G.S. \& Zaneveld, L.J.D. (1979) Distribution of spermatozoa in the rabbit vas deferens. Biol. Reprod. 21, 181-185.

Van Welkenhuyzen, P. (1966) La motilité du canal deferent. Acta Urol. Bel. 34, 385.

Wilhelm, S.F. (1935) Observations on the emptying of the vasa deferentia and seminal vesicles. J. Urol. 34, 284-287.

Received 18 April 1979 